\title{
High-grade Cervical Histopathology in Women with Atypical Glandular Cell Cytology
}

\author{
Waranya Watcharanon, Sanguanchoke Luanratanakorn, Pilaiwan Kleebkaow, \\ Bandit Chumworathayi,Amornrat Temtanakitpaisan, Chumnan Kietpeerakool*
}

\begin{abstract}
This study was undertaken to evaluate the prevalence of underlying significant lesions among women referred for colposcopy after atypical glandular cell (AGC) smears and the associated risks. The present study reviewed data from women with AGC smears undergoing colposcopy at the Colposcopy Clinic, Faculty of Medicine, Khon Kaen University, Thailand between January 2001 to December 2014. Significant lesions included cervical intraepithelial neoplasia grade 2-3, adenocarcinoma in situ, endometrial hyperplasia, and cancer. During the study period, 170 women with AGC cytology were reviewed. The mean age was 45.7 years. Thirty-eight women (22.4\%) were postmenopausal. Eighteen smears (10.6\%) were further subclassified as AGC-favor neoplasia (AGC-FN). In total, significant lesions were noted in 27 women (15.9\%; 95\% CI, 7.8\%-18.3\%). Thirteen women $(7.6 \%, 95 \% \mathrm{CI}, 4.1 \%-12.7 \%)$ were found to have cervical cancer or endometrial cancer. Two variables were independently associated with an increased risk of significant histopathology results: level of educational attainment (secondary level or lower versus bachelor degree or higher) and types of AGC (AGC versus AGCFN). Women who had low level of education and those with AGC-FN were at the higher risk of significant lesions (OR, 3.16; 95\% CI 1.10-9.11 and OR, 4.62; 95\% CI, 1.54-13.85, respectively). In conclusion, the rate of significant lesions among women referred for colposcopy after AGC smears is considerably high. Low education and smear subtypes appear independently associated with a higher risk of significant lesions.
\end{abstract}

Keywords: Atypical glandular cell - cervical smear - histology - predictor

Asian Pac J Cancer Prev, 17 (1), 135-138

\section{Introduction}

Because of a low coverage rate of screening, cervical cancer remains a major health problem in Thailand. In the recent population-based survey, Thailand is considered as an area with a high incidence of cervical cancer. When stratified by regions of Thailand, the highest incidence of cervical cancer was noted in Chiang Mai Province with an age-standardized incidence rate (ASR) of 28.9 per 100000, followed by Lampang Province (ASR, 22.4 per 100000). In Khon Kaen, a Province in Northeast Part of Thailand, an ASR of cervical cancer was 16.5 per 100000 (Moore et al., 2010).

Although there are various screening methods have been developed, cervical cytology remains the principal screening method. Atypical glandular cell (AGC) is a one of abnormal cervical cytology category that has been proposed by the 2001 Bethesda System for nomenclature of cervicovaginal cytology. The AGC category may be further subclassified as AGC, favor neoplasia (AGC-FN) if there are some cytological features suggesting high-grade cellular abnormality (Apgar et al., 2003). Management of first choice for AGC cytology is immediate colposcopy
(Massad et al., 2013).

As the risks of encountering significant lesions after abnormal cervical cytology vary among the different regions, data regarding the prevalence and histological types of these underlying significant lesions among each areas or population are mandatory for assessing and designing area-specific management strategies (AueAungkul et al., 2011; Kietpeerakool et al., 2014; Paengchit et al., 2014). This study was accordingly undertaken to evaluate the prevalence of underlying significant lesions among women referred for colposcopy after AGC cervical cytology and the associated risks.

\section{Materials and Methods}

In our institute, we recommended immediate colposcopy for all women with AGC cytology. The present study was a retrospective analysis of data from women with AGC cytology who underwent immediate colposcopy at Colposcopy Clinic, Srinagarind Hospital, Faculty of Medicine, Khon Kaen University, Thailand between January 2001 to December 2014. This study was approved by the Research Ethic Committee, Khon Kaen University. 
Abstracted data included patients' baseline characteristics, types of AGC cytology, types of colposcopic procedure carried out, and histopathological findings.

Colposcopic examination was performed following the application of 5\% acetic acid solution on the upper vagina and cervix. The severity of colposcopic findings was based on the density of acetowhite areas, sharpness of the lesion margins, and abnormal and atypical vascular patterns.

Colposcopy management in this study was according to the recommendation by the American Society for Colposcopy and Cervical Pathology (ASCCP) guidelines (Massad, et al., 2013). Conclusively, for AGC cytology, colposcopy with endocervical evaluation was carried out, with or without biopsy. Endometrial tissue examination was solely carried out for women with abnormal bleeding or who were over 35 years of age. In women with AGCFN smears, initial management was similar to that for AGC smears. However, if the initial result did not indicate endometrial lesions and the lesion severity was less than invasive cervical cancer, diagnostic cervical conization was then recommended.

The final histological diagnosis was made on the most

Table 1. Baseline Characteristics of Patients $(n=170)$

\begin{tabular}{|c|c|}
\hline Characteristics & Number $(\%)$ \\
\hline \multicolumn{2}{|l|}{$\overline{\text { Parity status }}$} \\
\hline Nulliparity & $21(12.4)$ \\
\hline Multiparity & $149(87.6)$ \\
\hline \multicolumn{2}{|l|}{ Menopausal status } \\
\hline Postmenopause & $38(22.4)$ \\
\hline Premenopause & $132(77.6)$ \\
\hline \multicolumn{2}{|l|}{ Educational attainment } \\
\hline Secondary education or lower & $108(63.5)$ \\
\hline Bachelor degree or higher & $62(36.5)$ \\
\hline \multicolumn{2}{|l|}{ Cytology types } \\
\hline $\mathrm{AGC}$ & $152(89.4)$ \\
\hline AGC-FN & $18(10.6)$ \\
\hline \multicolumn{2}{|l|}{ Colposcopy procedures } \\
\hline $\mathrm{CDB}$ & $8(4.7)$ \\
\hline ECC & $23(13.5)$ \\
\hline ES & $3(1.8)$ \\
\hline CDB with ECC & $22(12.9)$ \\
\hline LEEP & $1(0.6)$ \\
\hline LEEP with ECC & $39(22.9)$ \\
\hline LEEP with ECC with ES/curettage & $20(11.8)$ \\
\hline CDB with ECC with ES & $21(12.4)$ \\
\hline ECC with ES & $23(13.5)$ \\
\hline CDB with ES & $2(1.2)$ \\
\hline CDB with FC & $3(1.8)$ \\
\hline CKC with ECC & $2(1.2)$ \\
\hline $\mathrm{FC}$ & $1(0.6)$ \\
\hline Not done & $2(1.2)$ \\
\hline \multicolumn{2}{|l|}{ Histopathology results } \\
\hline Normal & $110(64.7)$ \\
\hline CIN 1 & $33(19.4)$ \\
\hline CIN 2-3 & $5 \quad(2.9)$ \\
\hline AIS & $6(3.5)$ \\
\hline CIN 2-3 with AIS & $2(1.2)$ \\
\hline Endometrial hyperplasia & $1(0.6)$ \\
\hline Cervical cancer & $7(4.1)$ \\
\hline Endometrial cancer & $6 \quad(3.5)$ \\
\hline
\end{tabular}

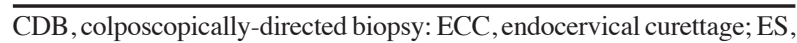
endometrial sampling; LEEP, loop electrosurgical excision procedure; $\mathrm{CKC}$, cold-knife conization; FC, fractional curettage severe histological results obtained after initial colposcopy. Significant histopathology included cervical intraepithelial neoplasia grade 2-3 (CIN 2-3), adenocarcinoma in situ (AIS), endometrial hyperplasia, and cancer of any original sites. All surgical pathology slides were reported by P.K. who was the gynecologic pathologist in our hospital.

Statistical analysis was carried out with SPSS software (IBM, Armonk, NY, USA). Descriptive statistics were used for demographic baseline characteristics. Analysis using the $\chi 2$ and Fisher's exact test was carried out to identify variables potentially associated with underlying significant histopathology results, including age, parity, menopausal status, bleeding symptom, education level, and AGC types. These variables were then included (if $\mathrm{P}<0.10$ ) in a stepwise logistic regression analysis to determine which, if any, were independently associated with the risk of encountering significant histopathology results. Adjusted odds ratio with a $95 \%$ confidence interval (CI), which did not include unity were considered statistically significant.

\section{Results}

During the study period, 170 women with AGC cytology were reviewed. The mean age \pm standard deviation (SD) was $45.7 \pm 9.5$ years (median, 46 years; range 17-79 years). Almost all of cervical cytologies in the present study $(97.1 \%)$ were conventional smears. Thirtyone women $(18.2 \%)$ had history of abnormal vaginal bleeding. Table 1 shows the baseline characteristics, types of AGC cytology, diagnostic procedures carried out during colposcopy, and detailed histopathology results. Twentyone women (12.4\%) were nulliparous. Thirty-eight women (22.4\%) were postmenopausal. Eighteen smears (10.6\%) were further subclassified as AGC-FN.

Table 3. Variables Associated with Underlying Significant Histopathology Results

\begin{tabular}{|c|c|c|c|}
\hline \multirow{2}{*}{$\begin{array}{l}\text { Variable } \\
\text { Menopausal status }\end{array}$} & \multicolumn{2}{|c|}{$\begin{array}{l}\text { Significant } \mathrm{P} \text {-value } \\
\text { histology results }^{\mathrm{b}}\end{array}$} & \multirow[t]{2}{*}{$\begin{array}{l}\text { Adjusted OR } \\
(95 \% \mathrm{CI})\end{array}$} \\
\hline & & & \\
\hline Postmenopause & $23.70 \%$ & \multirow[t]{2}{*}{0.135} & \multirow[t]{2}{*}{ Variable removed } \\
\hline Premenopause & $13.60 \%$ & & \\
\hline \multicolumn{4}{|l|}{ Parity status } \\
\hline Nulliparity & $14.30 \%$ & \multirow[t]{2}{*}{0.831} & \multirow[t]{2}{*}{ Variable removed } \\
\hline Multiparity & $16.10 \%$ & & \\
\hline \multicolumn{4}{|l|}{ Bleeding symptoms } \\
\hline Present & $19.40 \%$ & \multirow[t]{2}{*}{0.559} & \multirow[t]{2}{*}{ Variable removed } \\
\hline Absent & $15.10 \%$ & & \\
\hline \multicolumn{4}{|l|}{ Age (years) } \\
\hline$\geq 40$ & $17.70 \%$ & \multirow[t]{2}{*}{0.184} & \multirow[t]{2}{*}{ Variable removed } \\
\hline$<40$ & $8.6 \% \%$ & & \\
\hline \multicolumn{4}{|l|}{ Education attainment } \\
\hline \multicolumn{2}{|c|}{ Secondary level or lower $20.40 \%$} & \multirow[t]{2}{*}{0.035} & \multirow[t]{2}{*}{$3.16(1.10-9.11)$} \\
\hline Bachelor or higher & $8.10 \%$ & & \\
\hline \multicolumn{4}{|l|}{ Smear types } \\
\hline AGC-FN & $38.90 \%$ & \multirow[t]{2}{*}{0.005} & \multirow[t]{2}{*}{$4.62(1.54-13.85)$} \\
\hline AGC & $13.20 \%$ & & \\
\hline
\end{tabular}

OR, odds ratio; CI, confidence interval; AGC, atypical glandular cell; AGC-FN, atypical glandular cell-favor neoplasia; ' Including CIN 2-3, AIS, endometrial hyperplasia, and cancer of any original sites; ${ }^{\mathrm{b}}$ From univariate analyses 
Table 2. Histopathology Results Stratified by Patients' Characteristics and Smear Types

\begin{tabular}{|c|c|c|c|c|c|c|c|c|c|}
\hline \multirow[t]{2}{*}{ Variables } & & \multicolumn{8}{|c|}{ Histopathology results } \\
\hline & & $\mathrm{CC}$ & $\mathrm{EC}$ & $\begin{array}{l}\text { CIN } \\
2-3\end{array}$ & AIS & $\begin{array}{c}\text { AIS, } \\
\text { CIN 2-3 }\end{array}$ & $\mathrm{EH}$ & CIN 1 & Normal \\
\hline \multirow[t]{2}{*}{ Age (years) } & $\begin{array}{l}\geq 40 \\
(\mathrm{n}=135)\end{array}$ & 6 & 6 & 4 & 5 & 2 & 1 & 22 & 89 \\
\hline & $\begin{array}{l}<40 \\
(\mathrm{n}=35)\end{array}$ & 1 & 0 & 1 & 1 & 0 & 0 & 11 & 21 \\
\hline \multirow[t]{2}{*}{ Parity status } & $\begin{array}{l}\text { Nulliparity } \\
(\mathrm{n}=21)\end{array}$ & 1 & 0 & 0 & 1 & 0 & 1 & 4 & 14 \\
\hline & Multiparity (n=149) & 6 & 6 & 5 & 5 & 2 & 0 & 29 & 96 \\
\hline \multirow[t]{2}{*}{ Menopausal status } & Postmenopause $(n=38)$ & 1 & 4 & 2 & 1 & 1 & 0 & 8 & 21 \\
\hline & $\begin{array}{l}\text { Premenopause } \\
(n=132)\end{array}$ & 6 & 2 & 3 & 5 & 1 & 1 & 25 & 89 \\
\hline \multirow[t]{2}{*}{ Bleeding symptom } & $\begin{array}{l}\text { Present } \\
(\mathrm{n}=31)\end{array}$ & 2 & 3 & 1 & 0 & 0 & 0 & 8 & 17 \\
\hline & $\begin{array}{l}\text { Absent } \\
(\mathrm{n}=139)\end{array}$ & 5 & 3 & 4 & 6 & 2 & 1 & 25 & 93 \\
\hline \multirow[t]{2}{*}{ Education level } & Secondary level or lower $(n=108)$ & 6 & 6 & 4 & 3 & 2 & 1 & 21 & 65 \\
\hline & Bachelor or higher $(n=62)$ & 1 & 0 & 1 & 3 & 0 & 0 & 12 & 45 \\
\hline \multirow[t]{6}{*}{ Smear types } & $\begin{array}{l}\text { AGC } \\
(n=34)\end{array}$ & 2 & 0 & 1 & 0 & 0 & 0 & 7 & 24 \\
\hline & $\begin{array}{l}\text { AGC, endocervix } \\
(\mathrm{n}=97)\end{array}$ & 3 & 0 & 3 & 2 & 2 & 0 & 18 & 69 \\
\hline & $\begin{array}{l}\text { AGC, endometrium } \\
(\mathrm{n}=21)\end{array}$ & 0 & 6 & 0 & 1 & 0 & 0 & 4 & 10 \\
\hline & $\begin{array}{l}\text { AGC-FN } \\
(n=7)\end{array}$ & 0 & 0 & 0 & 2 & 0 & 0 & 1 & 4 \\
\hline & $\begin{array}{l}\text { AGC-FN, endocervix } \\
(\mathrm{n}=8)\end{array}$ & 2 & 0 & 1 & 1 & 0 & 1 & 2 & 1 \\
\hline & $\begin{array}{l}\text { AGC-FN, endometrium } \\
(\mathrm{n}=3)\end{array}$ & 0 & 0 & 0 & 0 & 0 & 0 & 1 & 2 \\
\hline
\end{tabular}

In total, significant lesions included CIN 2-3, AIS, endometrial hyperplasia, cervical cancer, and endometrial cancer were noted in 27 women $(15.9 \%$; $95 \%$ CI, $7.8 \%$ $18.3 \%)$. Thirteen women $(7.6 \%, 95 \%$ CI, $4.1 \%-12.7 \%)$ were found to have cervical cancer (7) and endometrial cancer (6). Table 2 displays the histopathology results cross-tabulated with patients' characteristics and types AGC cytology.

Table 3 shows the associations of patients' characteristics, types of AGC cytology with the rate of significant histopathology results. Six dichotomous variables including menopausal status, parity status, history of abnormal vaginal bleeding, patients' age, educational attainment, and type of AGC cytology were determined via a stepwise logistic regression analysis to evaluate their independent impact on the risk of having significant histopathology results. Only two variables were independently associated with increased risk of encountering significant histopathology results: level of educational attainment (secondary level or lower versus Bachelor degree or higher) and types of AGC cytology (AGC versus AGC-FN). Women who had low level of education were at the higher risk of having significant histopathology results (adjusted OR, 3.16; 95\% CI 1.109.11). Women whose AGC smears were subclassified as AGC-FN were more likely to have significant histopathology results than were those who had AGC smears (adjusted OR, 4.62; 95\% CI, 1.54-13.85)

\section{Discussion}

In the present study, the rate of underlying significant histopathology results among women referred for colposcopy after AGC cervical cytology and the associated risk factors have been systematically evaluated. The rate of underlying significant histopathology results among women with AGC cytology in the present study was considerably high (15.9\%). Significant independent variables correlated with significant histopathology results were level of educational attainment and subtypes of AGC cytology. The present observations highlight that a group of women requires comprehensive evaluation during colposcopy.

Studies have consistently shown that AGC-FN smear is associated with a higher risk of underlying severe lesions (Westin et al., 2008; Zhao et al., 2009; Sawangsang et al., 2011; Chatchotikawong et al., 2012). Previous study from Chiang Mai, area with the highest incidence of cervical cancer in Thailand reported that the rate of significant lesions among women with AGC-FN smears was $41.2 \%$ which was notably higher than women with AGC smears (15.2\%)(Sawangsang et al., 2011). In a study which was conducted in Bangkok, Thailand reaffirmed that as compared to AGC smears, women with smears interpreting AGC-FN, AGC-FN (endocervix), and AGCFN (endometrium) had, respectively, a 4.1-fold, 5.6-fold, and 8.2-fold higher risk of encountering significant 
histopathology results (Chatchotikawong et al., 2012). Similarly, women whose smears were further classified as AGC-FN smears in the present study were at the higher risk of having significant histopathology results as compared to those who had AGC smears (38.9\% versus 13.2\%; adjusted OR, 4.62; 95\%CI, 1.54-13.85).These findings support the appropriateness of the subcategorization of AGC cytology as per the recent Bethesda Nomenclature System in order to identify women who are at a higher risk of having underlying significant lesions.

Previous studies consistently reported that low socioeconomic status is directly associated with poor health (Ben-Shlomo et al., 1996; Veugelers and Yip, 2003). One of the potential explanations is a delayed access or even in unable to access the resources necessary to maintain good health among socioeconomically disadvantaged population (Falkingham et al., 2003; Schellenberg et al., 2003). Although there are various determinants of socioeconomic status, level of educational attainment has been identified as a good proxy (Falconer et al., 2015). Previous studies in Thailand identified that level of educational attainment may be one of the key factors predicting the risk of having severe histopathology results after abnormal cervical cancer screening (Paengchit et al., 2014; Supho et al., 2014). In the present study, women with low level of education attainment were approximately 3.2-fold more likely to have underlying significant histopathology results (adjusted OR, 3.16; 95\% CI 1.10-9.11). As women with low education may be less likely to access health care service including a regular cervical cancer screening, the strengthen risk of having significant lesions after abnormal screening results among women with low education therefore can be anticipated.

A notable finding in the present study was the high rate of underlying invasive cancer among women with AGC smears. In the present study, 13 women $(7.6 \%, 95 \%$ CI, $4.1 \%-12.7 \%$ ) were found to have cervical cancer and endometrial cancer. Previous studies demonstrated that the rate of underlying significant lesions particularly invasive cancer in women with abnormal cervical cancer screening in the areas with a high incidence of cervical cancer is relatively high when compare to that in low incidence population (Kietpeerakool et al., 2014).

Some limitations of this study are worthy of note. First, this study was retrospective; some clinically important data therefore may not be available, such as detailed sexual behavior and history of previous screening which might influence to the rate of underlying significant lesions. Second, this study contained a relatively small sample size which was secondary to the rarity of AGC smears. A lack of central slide review of cervical smears is another limitation. Results from this study could, however, be implemented in our actual situation since an effective system for central slide review of cervical cytology has not been established.

In conclusion, the rate of underlying significant lesions among women referred for colposcopy after AGC smears is considerably high. Low level of education attainment and interpreting AGC-FN smears were independently associated with higher risk of encountering significant lesions in the present study.

\section{References}

Apgar BS, Zoschnick L, Wright TC Jr (2003). The 2001 Bethesda System terminology. Am Fam Physician, 68, 1992-8.

Aue-Aungkul A, Punyawatanasin S, Natprathan A, et al (2011). "See and treat" approach is appropriate in women with highgrade lesions on either cervical cytology or colposcopy. Asian Pac J Cancer Prev, 12, 1723-6.

Ben-Shlomo Y, White IR, Marmot M (1996). Does the variation in the socioeconomic characteristics of an area affect mortality? BMJ, 312, 1013-4.

Chatchotikawong U, Ruengkhachorn I,Laiwejpithaya S (2012). Factors predicting pathologic significance among women with atypical glandular cells on liquid-based cytology. Int $J$ Gynaecol Obstet, 119, 30-4.

Falconer H, Yin L, Gronberg H, et al (2015). Ovarian cancer risk after salpingectomy: a nationwide population-based study. J Natl Cancer Inst, 107, 410.

Falkingham J (2003). Inequality and changes in women's use of maternal health-care services in Tajikistan. Stud Fam Plann, 34, 32-43.

Kietpeerakool C, Tangjitgamol S, Srisomboon J (2014). Histopathological outcomes of women with abnormal cervical cytology: a review of literature in Thailand. Asian Pac J Cancer Prev, 15, 6489-94.

Massad LS, Einstein MH, Huh WK, et al (2013). 2012 updated consensus guidelines for the management of abnormal cervical cancer screening tests and cancer precursors. Obstet Gynecol, 121, 829-46.

Moore MA, Attasara P, Khuhaprema T, et al (2010). Cancer epidemiology in mainland South-East Asia - past, present and future. Asian Pac J Cancer Prev, 11, 67-80.

Paengchit K, Kietpeerakool C, Lalitwongsa S(2014). Prevalence and genotype distribution of HPV among women attending a cervical cancer screening mobile unit in Lampang, Thailand. Asian Pac J Cancer Prev, 15, 6151-4.

Paengchit K, Kietpeerakool C, Wangchai W, et al (2014). Cervical pathology in cytology-negative/HPV-positive women: results from Lampang Cancer Hospital, Thailand. Asian Pac J Cancer Prev, 15, 7951-4.

Sawangsang P, Sae-Teng C, Suprasert P, et al (2011). Clinical significance of atypical glandular cells on Pap smears: experience from a region with a high incidence of cervical cancer. J Obstet Gynaecol Res, 37, 496-500.

Schellenberg JA, Victora CG, Mushi A, et al (2003). Inequities among the very poor: health care for children in rural southern Tanzania. Lancet, 361, 561-6.

Supho B, Supoken A, Kleebkaew P, et al (2014). Cervical pathology in high-risk human papillomavirus- positive, cytologically normal women. Asian Pac J Cancer Prev, 15, 7977-80.

Veugelers PJ,Yip AM (2003). Socioeconomic disparities in health care use: Does universal coverage reduce inequalities in health? J Epidemiol Community Health, 57, 424-8.

Westin MC, Derchain SF, Rabelo-Santos SH, et al (2008). Atypical glandular cells and adenocarcinoma in situ according to the Bethesda 2001 classification: cytohistological correlation and clinical implications. Eur J Obstet Gynecol Reprod Biol, 139, 79-85.

Zhao C, Florea A, Onisko A, et al (2009). Histologic follow-up results in 662 patients with Pap test findings of atypical glandular cells: results from a large academic womens hospital laboratory employing sensitive screening methods. Gynecol Oncol, 114, 383-9. 